\title{
Prototipe Sistem Pembuatan Larutan Nutrisi Otomatis pada Hidroponik Metode Nutrient Film Technique
}

\author{
Addy Rachmad Nurcahyo ${ }^{1}$, Kiki Prawiroredjo ${ }^{2}$, Susan Sulaiman ${ }^{3}$ \\ 1,2,3 Jurusan Teknik Elektro, \\ Fakultas Teknologi Industri, \\ Universitas Trisakti, Jakarta 11440 \\ 1addyrachmadn@gmail.com, ${ }^{2}$ kiki.prawiroredjo@trisakti.ac.id, ${ }^{3}$ susan@trisakti.ac.id
}

\begin{abstract}
Abstrak
Prototipe sistem pembuatan larutan nutrisi otomatis pada hidroponik nutrient film technique merupakan suatu sistem otomasi yang dapat mempermudah dan mempersingkat waktu pembudidaya dalam proses pembuatan larutan nutrisi untuk budidaya tanaman hidroponik. Pembuatan larutan nutrisi dilakukan secara otomatis sesuai dengan umur tanaman selada yang diatur menggunakan real time clock (RTC). Sistem yang dibuat terdiri dari sensor jarak ultrasonik sebagai pengukur ketinggian laruran nutrisi dan sensor total dissolved solids (TDS) untuk mengukur kadar total padatan terlarut. Sensor dihubungkan ke Arduino Mega 2560 sebagai komponen utama yang memproses sinyal masukan. Keluaran dari Arduino dikirim ke modul relay yang berfungsi sebagai saklar otomatis untuk mengatur kerja perangkat keluaran berupa pompa pengisian air, pompa sirkulasi, motor pengaduk dan solenoid valve. Pembuatan nutrisi dilakukan sebanyak 6 kali, yaitu pada umur 0 hari dan 7 hari dengan target TDS 600 ppm, umur 14 hari dan 21 hari dengan target TDS 700 ppm, umur 28 hari dan 35 hari dengan target TDS 800 ppm dan umur 42 hari dengan target TDS 850 ppm. Pembuatan larutan nutrisi dapat berjalan secara otomatis dengan kadar TDS larutan nutrisi yang dihasilkan pada tiap target pembuatan rata-rata sebesar $640 \mathrm{ppm}$, 716 ppm, 833 ppm dan 862 ppm dengan toleransi +50 ppm.
\end{abstract}

Kata kunci: Arduino Mega, hidroponik, nutrient film technique, selada, total dissolved solids

\begin{abstract}
The prototype of the automatic nutrient solution processing system in hydroponic nutrient film technique is an automatic system that simplify and shorten the time for cultivators in the process of making nutrient solutions. The preparation of nutrient solutions was carried out automatically according to the age of the lettuce plants which is set using a real time clock (RTC). The system made consists of an ultrasonic distance sensor to measure the height of the nutrient solution and a total dissolved solids (TDS) sensor to measure the TDS level of the nutrient solution. The sensors were connected to the Arduino Mega 2560 as the main component that processes the input signals. The Arduino output signal was sent to a relay module as an automatic switch to regulate the work of the output devices which included a water filling pump, a circulation pump, a stirrer motor and a solenoid valve. The nutrition was made 6 times, at $0^{\text {th }}$ and $7^{\text {th }}$ day with $600 \mathrm{ppm}$ TDS target, $14^{\text {th }}$ day and $21^{\text {st }}$ day with $700 \mathrm{ppm}$ TDS target, $28^{\text {th }}$ day and $35^{\text {th }}$ day with $800 \mathrm{ppm}$ TDS target and $42^{\text {nd }}$ day with 850 ppm TDS target. After being tested, the processing system ran automatically and the
\end{abstract}


average target of TDS levels of the nutrient solutions were $640 \mathrm{ppm}, 716 \mathrm{ppm}, 833 \mathrm{ppm}$ and 862 ppm with +50 ppm tolerance.

Keywords: Arduino Mega, hydroponic, lettuce, nutrient film technique, total dissolved solids

\section{Pendahuluan}

Hidroponik merupakan suatu cara budidaya tanaman tanpa menggunakan tanah tetapi diberikan larutan hara yang mengandung semua elemen esensial yang diperlukan untuk pertumbuhan dan perkembangan normal tanaman [1]. Hidroponik berasal dari bahasa Yunani, hidro berarti air dan ponous berarti bekerja [2]. Sistem hidroponik yang dilakukan tanpa menggunakan media tanah dapat menjadi solusi alternatif untuk efisiensi penggunaan lahan. [3]. Salah satu metode yang banyak digunakan adalah nutrient film technique (NFT) di mana larutan nutrisi akan mengalir secara terus menerus dan teratur [4]. NFT merupakan model budidaya hidroponik dengan meletakkan akar tanaman pada lapisan air yang dangkal. Air tersebut tersirkulasi dan mengandung nutrisi sesuai kebutuhan tanaman [5]. Teknik NFT telah digunakan di seluruh dunia karena kesuksesannya dalam menghasilkan pohon yang rindang dan menghemat air dari 70 sampai 90\% [6]. Budidaya tanaman dengan hidroponik sangat bergantung pada larutan nutrisi tersebut yang menjadi salah satu faktor penentu paling penting dalam menentukan hasil dan kualitas tanaman [7]. Kunci utama dalam pemberian larutan nutrisi atau pupuk pada sistem hidroponik adalah pengaturan kepekatan larutan nutrisi yang dinyatakan dengan total dissolved solids (TDS) atau total padatan terlarut dalam satuan part per million ( $\mathrm{ppm}$ ) atau bagian per sejuta. Setiap jenis dan umur tanaman membutuhkan larutan nutrisi dengan kadar TDS yang berbeda-beda. Kebutuhan TDS disesuaikan dengan fase pertumbuhan, yaitu ketika tanaman masih kecil, TDS yang dibutuhkan juga kecil. Semakin meningkat umur tanaman semakin besar TDS-nya [3]. Kadar TDS yang tidak tepat mempengaruhi penyerapan nutrisi oleh tanaman [8].

Pada sistem hidroponik yang dilakukan secara manual diperlukan ketepatan pengukuran untuk mendapatkan nilai ppm yang sesuai kebutuhan tiap jenis dan umur tanaman. Selain itu waktu yang dibutuhkan cukup banyak dan merepotkan. Pemberian larutan nutrisi dengan ppm yang tidak sesuai dengan umur tanaman dapat merusak akar tanaman dan mengganggu serapan nutrisi dan air [9]. Sistem yang dibuat ini berjalan otomatis menggunakan real time clock (RTC) sebagai pewaktu untuk pembuatan larutan nutrisi yang dilakukan per minggu, sensor jarak HC-SR04 sebagai masukan yang digunakan untuk mengukur ketinggian air pada wadah dan sensor TDS meter sebagai masukan yang digunakan untuk membaca nilai kepekatan larutan nutrisi. Mikrokontroler Arduino Mega 2560 digunakan sebagai pemroses masukan sensor untuk mengendalikan keluaran berupa solenoid valve, motor DC dan pompa air. Sensor TDS meter yang digunakan mempunyai batas pengukuran pada rentang $0-1000$ ppm sehingga hanya dapat digunakan pada tanaman dengan kebutuhan nutrisi $<1000$ ppm.

\section{Kajian Pustaka}

Beberapa penelitian yang telah dilakukan di antaranya otomatisasi pengendalian cara pengairan dan pemberian nutrisi pada sistem tanam hidroponik untuk tanaman selada [10]. Pada penelitian tersebut dibuat sebuah sistem kontrol pengendalian air otomatis dengan sistem On-Off untuk tanaman selada menggunakan hidroponik sistem 
sumbu (wick). Ketinggian volume air di dalam media hidroponik dikontrol secara otomatis menggunakan elektroda.

Pada penelitian [11], pengisian dan sirkulasi larutan nutrisi hidroponik dirancang menggunakan sistem wick secara otomatis. Sistem mampu mendeteksi ketinggian larutan di talang penanaman menggunakan sensor ultrasonik dan dilengkapi dengan sensor suhu untuk mendeteksi suhu larutan nutrisi. Data ketinggian dan suhu larutan nutrisi dapat dipantau melalui perangkat Android.

Pada penelitian [12] telah dibuat sistem pemberian air dan nutrisi secara otomatis dengan mengatur waktu membuka dan menutup valve air. Pada sistem ini proses pembuatan larutan nutrisi dilakukan secara otomatis dengan mengatur waktu buka valve yang terdapat di wadah nutrisi A dan nutrisi B hingga mencapai $350 \mathrm{ml}$. Kemudian dilanjutkan dengan pengisian air baku hingga mencapai batas atas wadah pencampur yang dibatasi oleh sensor level kapasitif yang dilanjutkan dengan proses pengadukan.

Sementara pada penelitian [13], dibuat suatu sistem pengairan pada hidroponik sistem NFT yang dapat mengendalikan sirkulasi air pada saat pompa sirkulasi tidak mendapatkan daya listrik dan sistem pengairan yang dapat mengendalikan kelebihan air pada tangki penampungan nutrisi saat kondisi hujan.

\section{Metode Penelitian}

Mekanisme perancangan sistem meliputi perancangan diagram blok sistem, perancangan bagian elektronik, bagian software dan bagian mekanik. Setelah tiap bagian sistem dibuat dilakukan pengujian, hasil pengujian dianalisis dan ditarik kesimpulan.

\subsection{Diagram Blok Sistem}

Diagram blok sistem secara keseluruhan dari alat yang dibuat diperlihatkan pada Gambar 1.

Secara umum diagram blok sistem memiliki tiga bagian, yaitu masukan, proses atau pengendali utama dan keluaran. Bagian pengendali utama menggunakan mikrokontroler Arduino Mega 2560 yang menyesuaikan kebutuhan I/O pada sistem yang dibuat. Sedangkan pada bagian masukan dan keluaran dapat dijelaskan sebagai berikut:

a. Bagian masukan Arduino:

1) Sensor TDS analog, berfungsi untuk mengetahui kadar total padatan terlarut pada larutan nutrisi yang dibuat pada wadah pencampur.

2) Sensor ultrasonik HC-SR04, berfungsi untuk membaca ketinggian air pada wadah pencampur. Pemilihan sensor ini karena lebih mudah digunakan dibandingkan dengan sensor elektroda di mana hasil output yang didapat menunjukkan nilai ketinggian air pada tangki. Selain itu sensor ini tidak terkena air secara langsung.

3) PushButton, digunakan untuk memilih jenis tanaman yang ditanam.

4) Modul RTC, berfungsi untuk menghitung umur tanaman.

b. Bagian keluaran Arduino:

1) Relay module, berfungsi sebagai saklar elektronik yang berguna untuk mengaktifkan atau memutus aliran listrik aktuator yang digunakan.

2) Solenoid valve 1 berfungsi sebagai kran untuk mengalirkan air baku dari wadah berisi air baku ke wadah pencampur. 


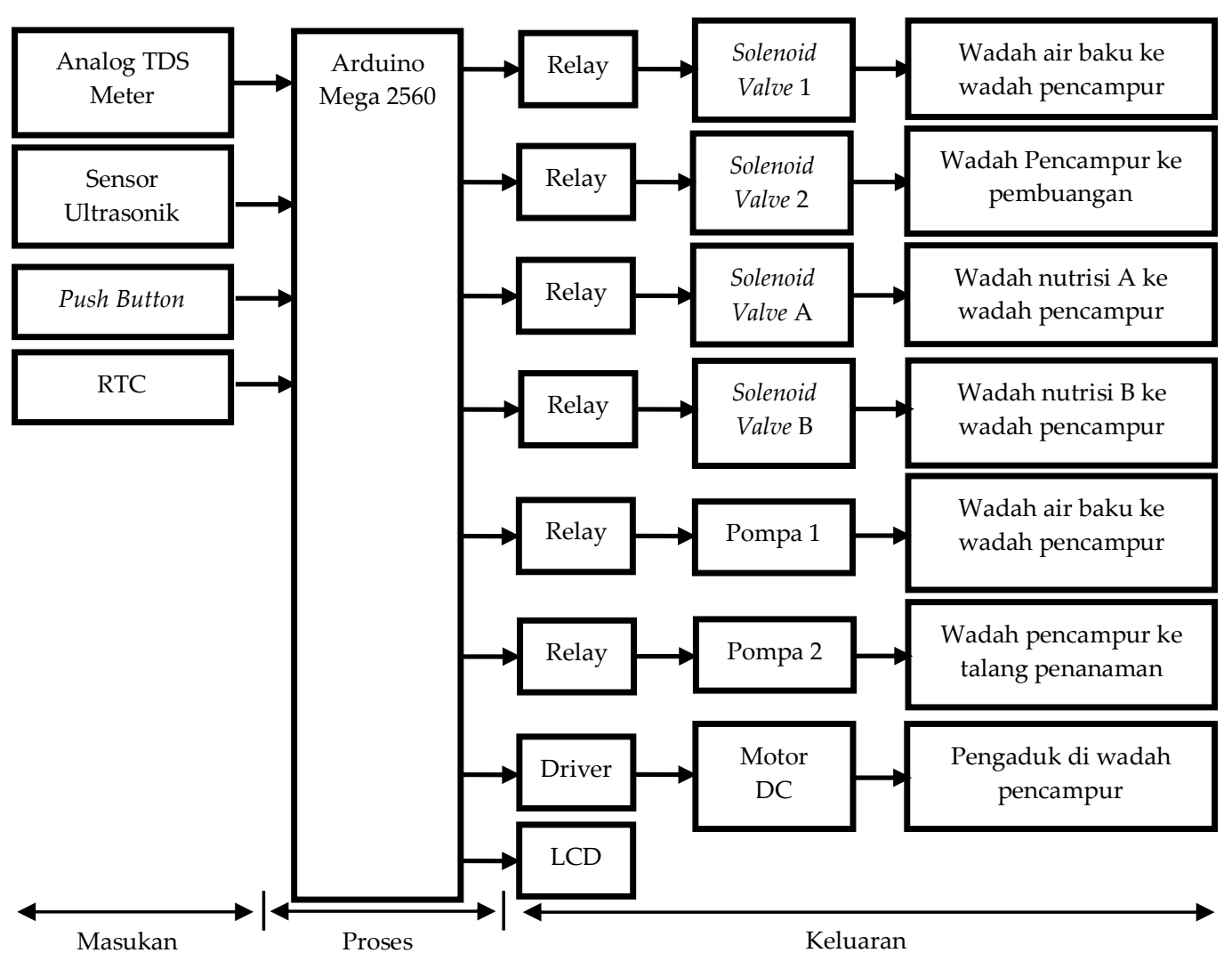

Gambar 1. Diagram Blok Sistem

3) Solenoid valve A berfungsi sebagai kran untuk mengalirkan nutrisi A ke wadah pencampur.

4) Solenoid valve B berfungsi sebagai kran untuk mengalirkan nutrisi B ke wadah pencampur.

5) Solenoid valve 2 berfungsi sebagai kran pembuangan larutan nutrisi dari wadah pencampur.

6) Pompa 1 berfungsi sebagai pompa yang digunakan untuk proses pengisian air baku untuk pembuatan larutan nutrisi.

7) Pompa 2 berfungsi sebagai pompa yang digunakan untuk proses sirkulasi pemberian nutrisi.

8) Motor DC $12 \mathrm{~V}$ berfungsi sebagai pengaduk saat proses pencampuran air dan nutrisi $\mathrm{AB}$ mix pada wadah pencampur agar larutan nutrisi tercampur rata.

9) LCD berfungsi untuk menampilkan informasi.

\subsection{Perancangan Rangkaian}

Rangkaian secara keseluruhan terdapat pada Gambar 2 terdiri dari bagian masukan, proses dan keluaran. 
Prototipe Sistem Pembuatan Larutan Nutrisi Otomatis pada Hidroponik Metode Nutrient Film Technique Addy Rachmad Nurcahyo, Kiki Prawiroredjo, Susan Sulaiman

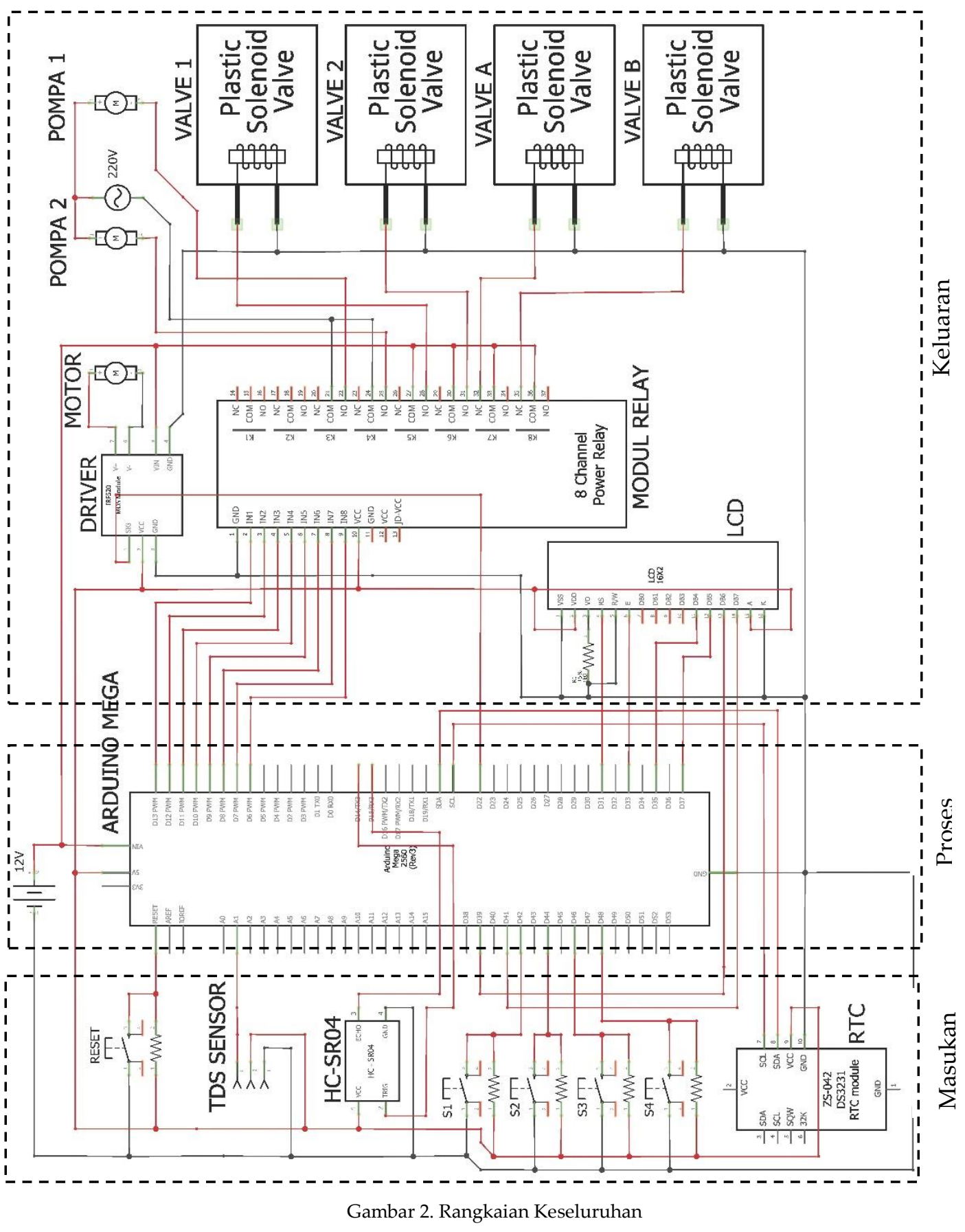

Keterangan perangkat keras sesuai dengan keterangan di diagram blok sistem.

\subsection{Perancangan Perangkat Lunak}

Pada Gambar 3 terdapat diagram alir sistem secara keseluruhan. Terdapat 4 jenis pilihan tanaman yang dapat dipilih yaitu selada, kangkung, bayam dan pakcoy. Keempat pilihan tanaman tersebut masing-masing memiliki pemrograman software yang berbeda sesuai dengan kebutuhan nutrisinya. 


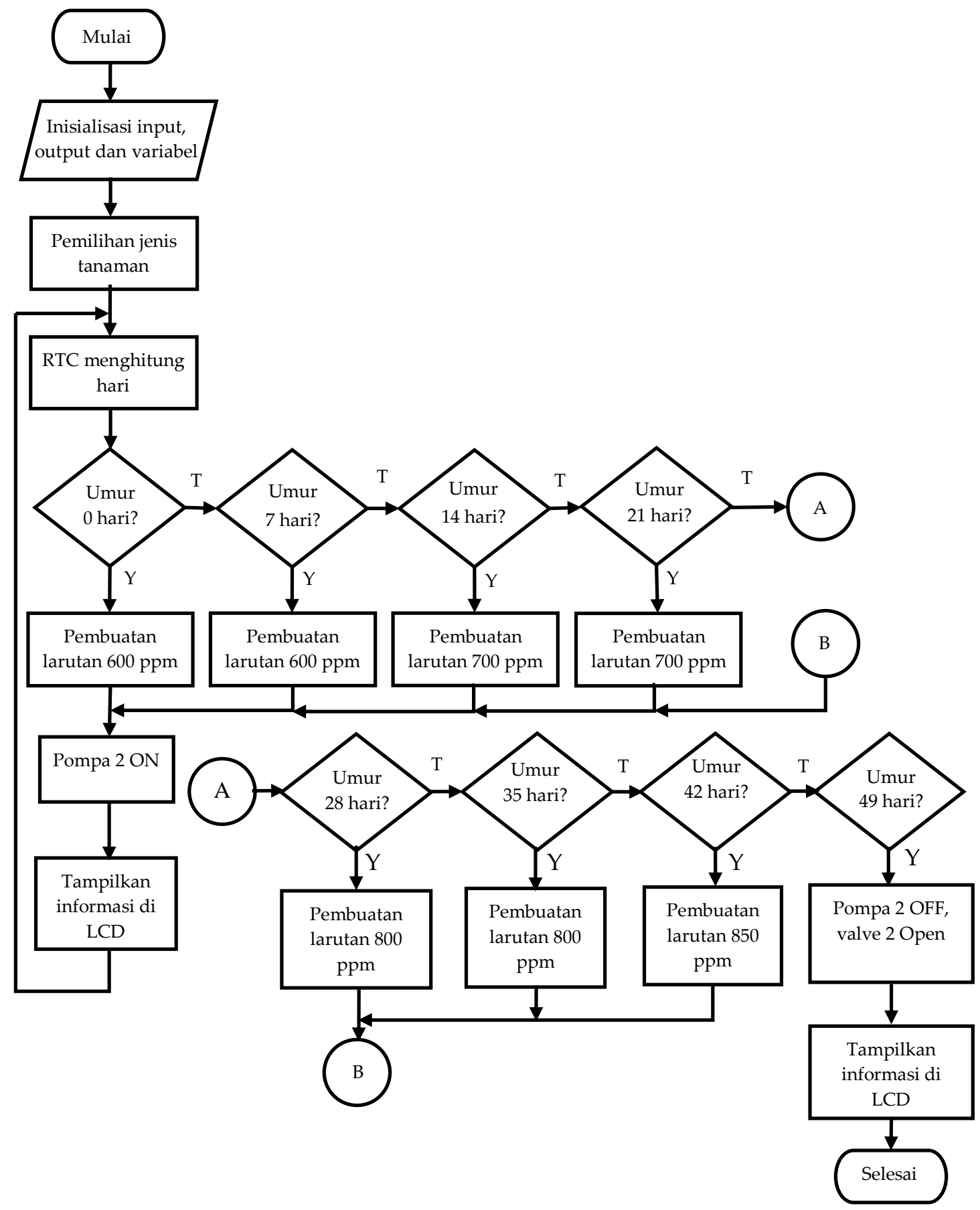

Gambar 3. Diagram Alir Sistem

Gambar 3 merupakan diagram alir sistem jadual pembuatan larutan nutrisi dan besarnya nilai ppm pada larutan hidroponik sistem NFT. Proses dimulai dengan memilih jenis tanaman yang akan ditanam menggunakan push button dengan informasi yang ditampilkan melalui LCD.

Proses selanjutnya RTC melakukan perhitungan hari sebagai umur tanaman dan ditampilkan pada LCD, jika umur menunjukkan hasil 0 hari maka sistem akan membuat campuran larutan nutrisi 600 ppm. Jika umur menunjukkan 7 hari maka akan dibuat 
campuran larutan nutrisi 600 ppm. Jika umur menunjukkan 14 hari maka akan dibuat campuran larutan nutrisi 700 ppm. Jika umur menunjukkan 21 hari maka akan dibuat campuran larutan nutrisi 700 ppm. Jika umur menunjukkan 28 hari maka akan dibuat campuran larutan nutrisi $800 \mathrm{ppm}$. Jika umur menunjukkan 35 hari maka akan dibuat campuran larutan nutrisi 800 ppm. Jika umur menunjukkan 42 hari maka akan dibuat campuran larutan nutrisi $850 \mathrm{ppm}$. Jika umur menunjukkan 49 hari maka proses penanaman selesai dan wadah penampungan dikosongkan. Pengaturan jadwal penggantian dan nilai ppm larutan nutrisi tersebut adalah untuk tanaman selada [14]. Selama proses bekerjanya alat, diperlukan suplai daya yang harus terus tersambung. Jika terdapat keadaan suplai daya terputus maka diperlukan fitur tambahan untuk melakukan penyimpanan data umur tanaman pada memori EEPROM internal modul Arduino agar proses bekerjanya alat dapat kembali dilanjutkan sesuai dengan status terakhir. EEPROM ini memiliki alamat dan sejumlah memori dimana data yang disimpan tidak akan terhapus walau tanpa dialiri listrik [15]. Setelah pembuatan larutan nutrisi selesai, pompa 2 akan On untuk mendistribusikan larutan nutrisi ke tanaman. Pada Gambar 4 diperlihatkan proses pembuatan larutan nutrisi.

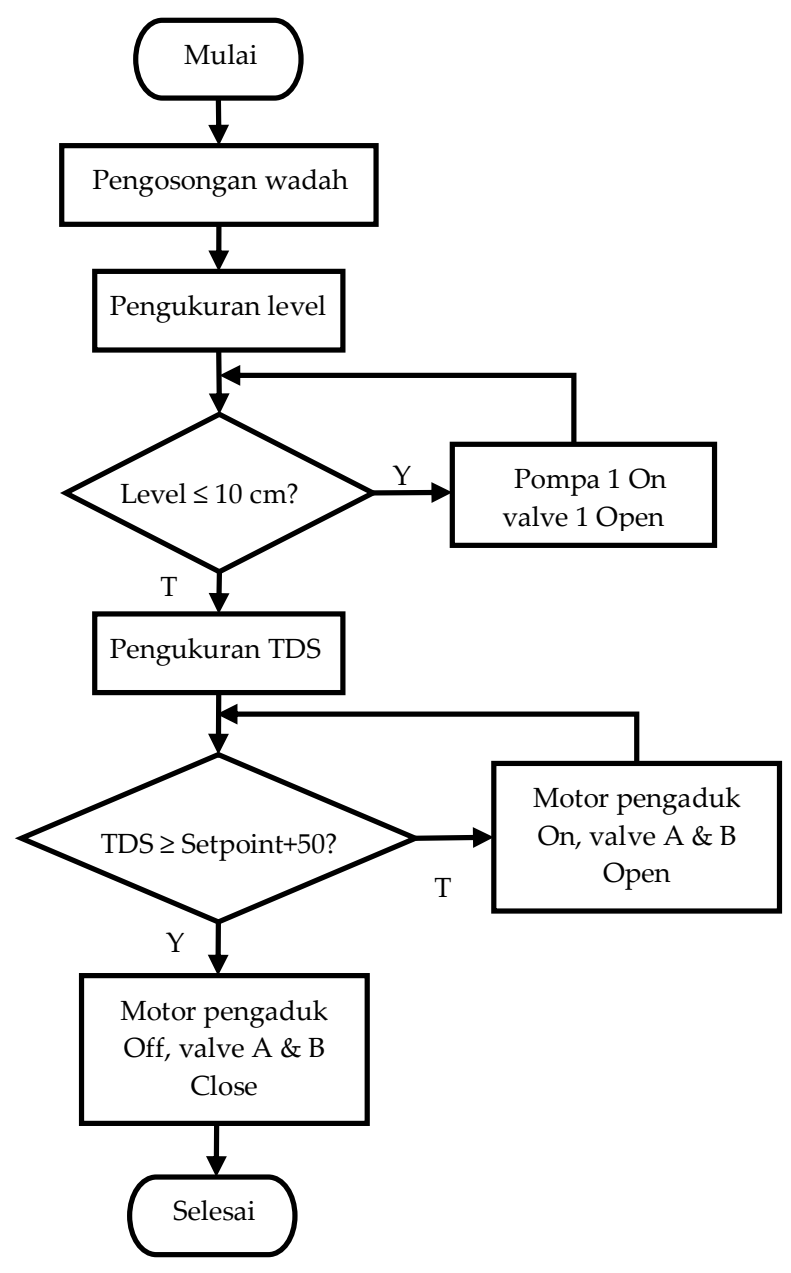

Gambar 4. Diagram Alir Pembuatan Larutan Nutrisi

Berdasarkan Gambar 4 di atas, dapat dilihat bahwa pada proses pembuatan larutan nutrisi mula-mula akan dilakukan pengosongan wadah dari larutan nutrisi sebelumnya, 
kemudian dilakukan pengukuran level larutan nutrisi pada wadah penampung. Pada proses pengisian air baku, ketinggian air dibatasi dengan tinggi maksimal $10 \mathrm{~cm}$. Hal ini disesuaikan dengan ukuran wadah penampungnya. Jika level terbaca $0 \mathrm{~cm}$ atau kurang dari $10 \mathrm{~cm}$, maka Arduino akan memberikan sinyal keluaran untuk pengisian air baku dengan menyalakan pompa 1 . Jika level sudah mencapai lebih dari $10 \mathrm{~cm}$, maka proses pengisian air baku selesai. Selanjutnya, sensor TDS melakukan pengukuran kadar TDS pada air yang ada pada wadah. Jika pengukuran menunjukkan hasil kurang dari setpoint maka motor pengaduk menyala, solenoid valve A dan B terbuka secara bersamaan hingga kadar TDS larutan pada wadah penampung tercapai. Jika kadar TDS sudah sesuai dengan setpoint yang ditentukan, maka Arduino akan mengirimkan perintah untuk mematikan motor pengaduk dan menutup solenoid valve A dan B karena proses pembuatan larutan nutrisi telah selesai.

\subsection{Perancangan Mekanik}

Dalam perancangan prototipe alat ini terdapat desain instalasi hidroponik dan penggabungan dari tiap komponen-komponen yang digunakan agar alat yang dibuat sesuai dengan perancangan dan berfungsi sesuai dengan spesifikasi yang diinginkan seperti yang terdapat pada Gambar 5 dan Gambar 6.

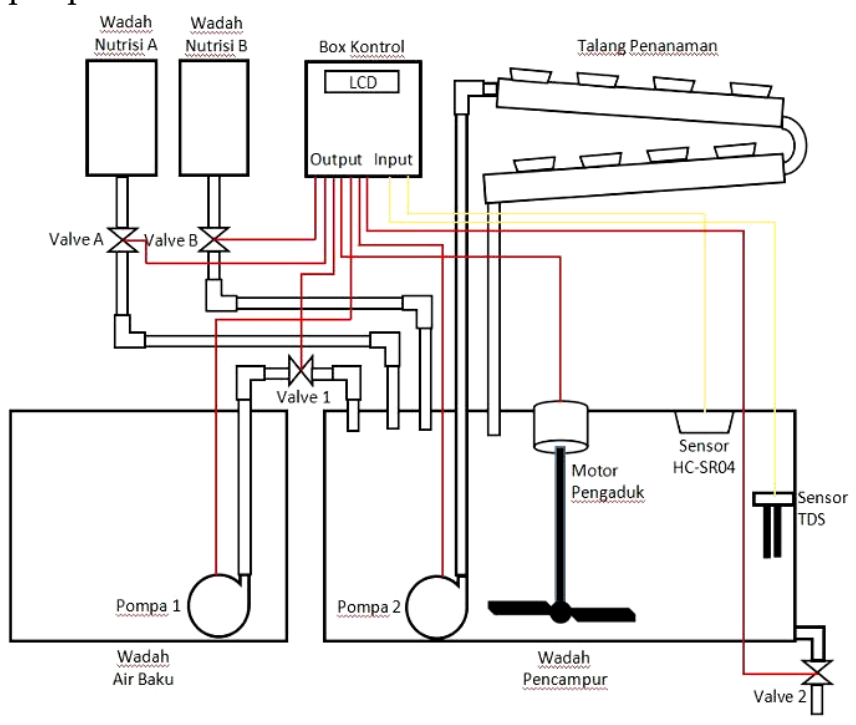

Gambar 5. Skema Perancangan Instalasi Hidroponik

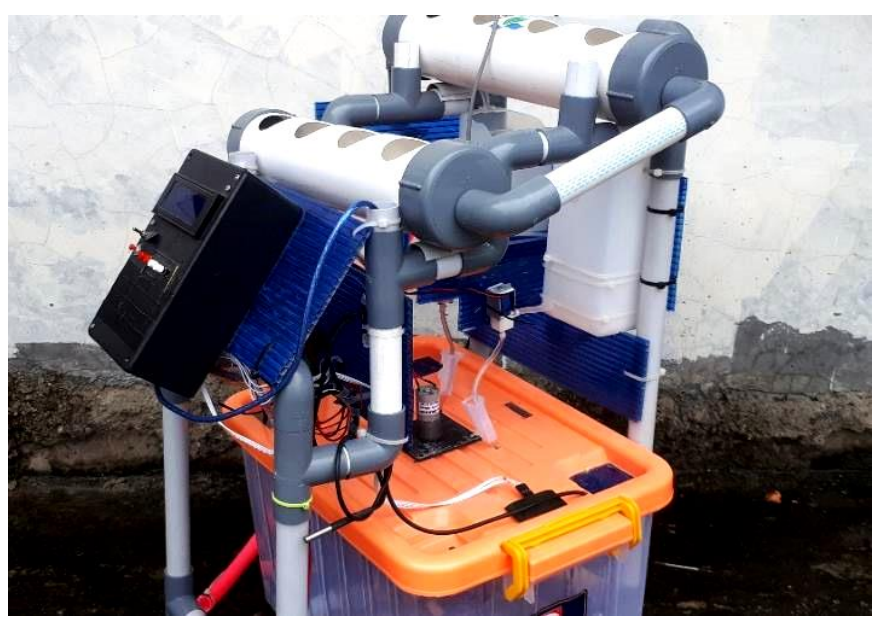

Gambar 6. Realisasi Instalasi Hidroponik 
Bahan utama yang digunakan terbuat dari pipa pvc yang dirancang dan disusun sedemikian rupa menjadi instalasi hidroponik sistem NFT. Wadah untuk penampungan larutan nutrisi memakai wadah plastik dengan dimensi $40 \times 25 \times 26 \mathrm{~cm}$, wadah nutrisi $\mathrm{AB}$ mix menggunakan wadah plastik dengan ukuran $8 \times 8 \times 18 \mathrm{~cm}$ dan kotak hitam yang digunakan untuk meletakkan Arduino dan rangkaian kontrol. Dimensi alat secara keseluruhan adalah $50 \times 50 \times 70 \mathrm{~cm}$. Talang yang dibuat terdapat 8 lubang untuk tempat tanaman yang dibagi menjadi dua tingkat.

\section{Hasil dan Pembahasan}

Pengujian prototipe otomasi hidroponik sistem NFT ini dilakukan secara keseluruhan dengan menghubungkan semua perangkat masukan, kontroler dan perangkat keluaran. Pengujian secara keseluruhan merupakan pengujian otomasi sistem yang dilakukan untuk mengetahui kinerja dan fungsi prototipe yang telah dibuat.

\subsection{Pengujian Penghitungan Umur Tanaman}

Pengujian dilakukan untuk menguji ketepatan waktu RTC dalam menghitung umur tanaman yang digunakan sebagai acuan waktu pembuatan larutan nutrisi setiap 7 hari.

Tabel 1. Tabel Penghitungan Umur Tanaman

\begin{tabular}{|c|c|c|c|c|c|}
\hline No & Waktu RTC & Umur & No & Waktu RTC & Umur \\
\hline 1 & $12: 58: 35$ & 0 & 26 & $13: 23: 21$ & 25 \\
\hline 2 & 12:59:04 & 1 & 27 & 13:24:04 & 26 \\
\hline 3 & 13:00:07 & 2 & 28 & $13: 25: 12$ & 27 \\
\hline 4 & 13:01:07 & 3 & 29 & $13: 26: 04$ & 28 \\
\hline 5 & 13:02:08 & 4 & 30 & 13:27:08 & 29 \\
\hline 6 & 13:03:08 & 5 & 31 & $13: 28: 08$ & 30 \\
\hline 7 & 13:04:00 & 6 & 32 & 13:29:07 & 31 \\
\hline 8 & 13:05:02 & 7 & 33 & 13:30:09 & 32 \\
\hline 9 & 13:06:01 & 8 & 34 & $13: 31: 14$ & 33 \\
\hline 10 & 13:07:04 & 9 & 35 & 13:32:03 & 34 \\
\hline 11 & 13:08:09 & 10 & 36 & 13:33:03 & 35 \\
\hline 12 & 13:09:11 & 11 & 37 & $13: 34: 11$ & 36 \\
\hline 13 & 13:10:02 & 12 & 38 & 13:35:10 & 37 \\
\hline 14 & $13: 11: 50$ & 13 & 39 & $13: 36: 03$ & 38 \\
\hline 15 & 13:12:05 & 14 & 40 & $13: 37: 26$ & 39 \\
\hline 16 & 13:13:03 & 15 & 41 & 13:38:34 & 40 \\
\hline 17 & $13: 14: 06$ & 16 & 42 & 13:39:08 & 41 \\
\hline 18 & 13:15:13 & 17 & 43 & 13:40:11 & 42 \\
\hline 19 & $13: 16: 10$ & 18 & 44 & 13:41:09 & 43 \\
\hline 20 & 13:17:04 & 19 & 45 & $13: 42: 03$ & 44 \\
\hline 21 & 13:18:06 & 20 & 46 & 13:43:00 & 45 \\
\hline 22 & 13:19:02 & 21 & 47 & 13:44:01 & 46 \\
\hline 23 & $13: 20: 12$ & 22 & 48 & 13:45:04 & 47 \\
\hline 24 & 13:21:02 & 23 & 49 & $13: 46: 10$ & 48 \\
\hline 25 & $13: 22: 10$ & 24 & 50 & 13:47:03 & 49 \\
\hline
\end{tabular}


Penghitungan umur disimulasikan menggunakan data detik, yang berarti setiap 60 detik umur bertambah 1 hari. Pengujian dilakukan hingga umur panen tanaman selada atau 49 hari. Setiap 7 hari akan dilakukan penggantian larutan nutrisi yang disimulasikan dengan mencetak kalimat yang berbeda pada LCD. Hasil pengujian disajikan pada Tabel 1 .

Berdasarkan data hasil pengujian pada Tabel 1, dapat diamati bahwa penghitungan umur berjalan dengan benar dari umur 0 hari sampai dengan 49 hari, di mana setiap 60 detik umur bertambah 1 . Hasil pengujian simulasi yang diambil setiap umur 7 hari ditampilkan pada LCD dan diperlihatkan pada Gambar 7.

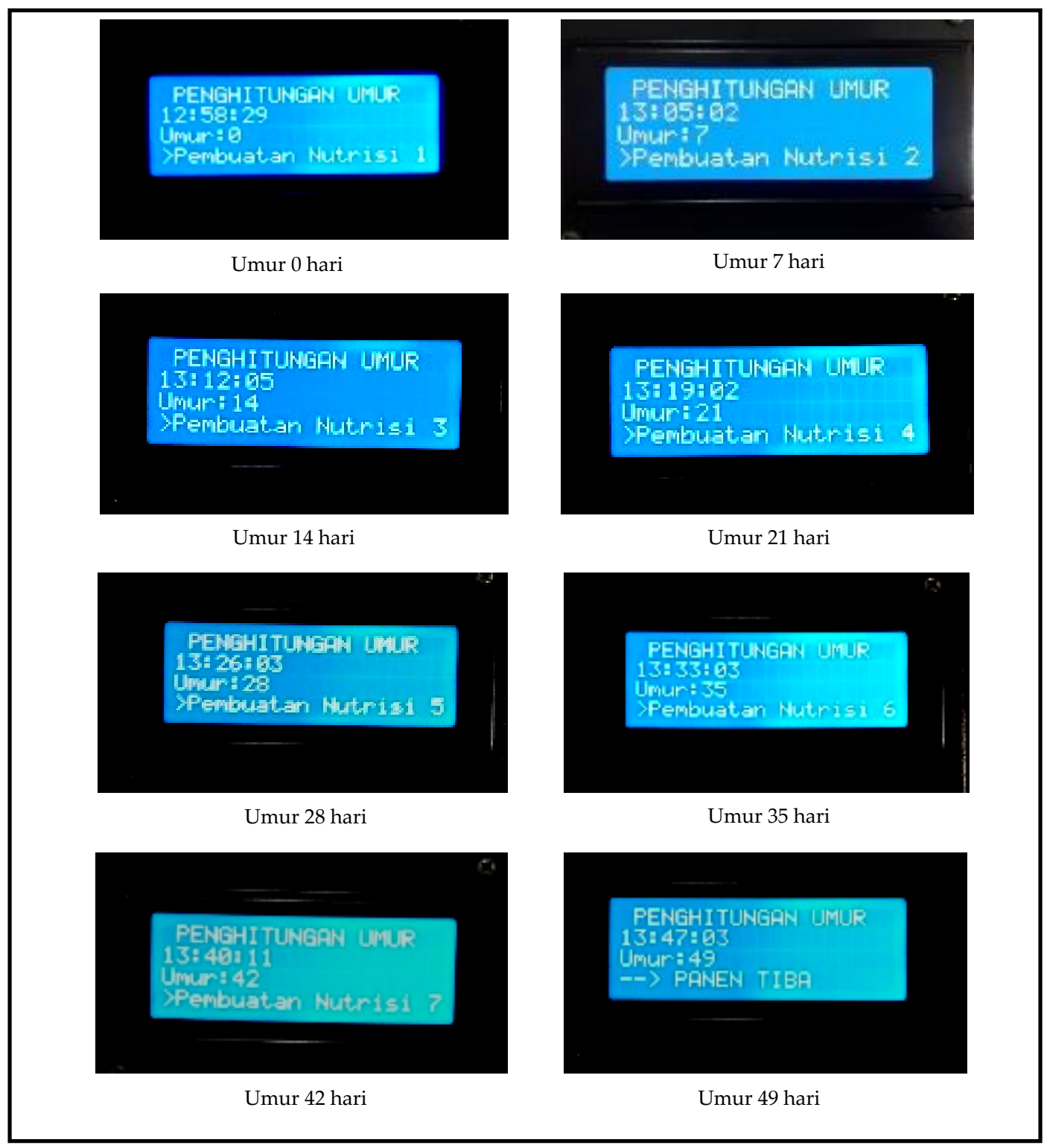

Gambar 7. Hasil Pengujian Umur Kelipatan 7

Pada setiap umur kelipatan 7 akan dieksekusi program untuk menampilkan suatu kalimat pada LCD sebagai simulasi pembuatan larutan nutrisi baru. Pada Gambar 7 dapat diamati bahwa sistem dapat mengeksekusi program untuk menampilkan kalimat 
yang berbeda pada LCD di baris ke-4. Program tersebut hanya dieksekusi saat umur 7 hari atau kelipatannya.

\subsection{Pengujian Pembuatan Larutan Nutrisi}

Pengujian ini merupakan pengujian sistem dalam membuat larutan nutrisi dengan kadar TDS tertentu yang telah ditentukan. Pengujian dilakukan dengan mengkondisikan alat untuk membuat larutan nutrisi dengan kadar TDS sebesar 600 ppm, 700 ppm, 800 ppm dan 850 ppm sesuai dengan kebutuhan selada dengan toleransi +50 ppm. Besaran toleransi tersebut tidak baku dan dapat diperkecil maupun diperbesar dengan pertimbangan agar kadar TDS dari hasil pembuatan larutan nutrisi tidak kurang dan tidak lebih besar terlalu jauh dari kebutuhan tanaman. Proses dimulai dari pengisian air baku yang dibatasi dengan tinggi $10 \mathrm{~cm}$. Kemudian proses dilanjutkan dengan pencampuran nutrisi AB Mix dengan kadar TDS. Pengujian dilakukan sebanyak tiga kali percobaan untuk medapatkan data yang lebih relevan. Tabel 2 merupakan hasil pengukuran sensor ultrasonik HC-SR04 dan TDS meter setelah proses pembuatan larutan nutrisi.

Tabel 2. Hasil Pengujian Pembuatan Larutan Nutrisi

\begin{tabular}{|c|c|c|c|c|c|c|c|c|c|}
\hline \multirow{2}{*}{ No } & \multirow{2}{*}{$\begin{array}{c}\text { Target } \\
\text { TDS }\end{array}$} & \multicolumn{2}{|c|}{ Pengujian ke-1 } & \multicolumn{2}{c|}{ Pengujian ke-2 } & \multicolumn{2}{c|}{ Pengujian ke-3 } & \multicolumn{2}{c|}{ Rata-rata } \\
\cline { 3 - 10 } & $\begin{array}{c}\text { HC- } \\
\text { SR04 }\end{array}$ & $\begin{array}{c}\text { TDS } \\
\text { Meter }\end{array}$ & $\begin{array}{c}\text { HC- } \\
\text { SR04 }\end{array}$ & $\begin{array}{c}\text { TDS } \\
\text { Meter }\end{array}$ & $\begin{array}{c}\text { HC- } \\
\text { SR04 }\end{array}$ & $\begin{array}{c}\text { TDS } \\
\text { Meter }\end{array}$ & $\begin{array}{c}\text { HC- } \\
\text { SR04 }\end{array}$ & $\begin{array}{c}\text { TDS } \\
\text { Meter }\end{array}$ \\
\hline 1 & 600 & 10 & 645 & 10 & 640 & 10 & 634 & 10 & 640 \\
\hline 2 & 700 & 11 & 723 & 10 & 715 & 11 & 709 & 11 & 716 \\
\hline 3 & 800 & 10 & 827 & 10 & 832 & 11 & 840 & 10 & 833 \\
\hline 4 & 850 & 10 & 852 & 10 & 870 & 11 & 863 & 10 & 862 \\
\hline
\end{tabular}

Berdasarkan data hasil pengujian dapat diamati bahwa respon aktuator bekerja sesuai dengan masukan sensor yang terukur. Pada kondisi pengisian air, valve 1 dan pompa 1 akan aktif untuk melakukan pengisian hingga level mencapai $10 \mathrm{~cm}$. Kemudian pada proses pencampuran nutrisi $\mathrm{AB}$ Mix, valve $\mathrm{A}$, valve $\mathrm{B}$ dan motor pengaduk akan aktif hingga kadar TDS terukur lebih dari target yang ditentukan. Saat kondisi sirkulasi, hanya pompa 2 yang aktif untuk melakukan sirkulasi. Dari pengujian pembuatan larutan nutrisi yang telah dilakukan, proses pembuatan larutan nutrisi dapat berjalan secara otomatis dengan kadar larutan nutrisi yang dihasilkan pada tiap target TDS rata-rata sebesar 640 ppm, 716 ppm, 833 ppm dan 862 ppm. Hasil pembuatan larutan nutrisi tersebut sesuai dengan yang direncanakan yaitu target TDS dengan toleransi +50 ppm.

\section{Kesimpulan}

Telah dibuat suatu prototipe sistem pembuatan larutan nutrisi otomatis pada hidroponik metode nutrient film technique untuk tanaman selada dengan hasil pengujian yang didapat yaitu sistem dapat bekerja dengan baik sesuai rancangan. Simulasi penghitungan umur tanaman yang dilakukan menggunakan modul RTC DS3231 berjalan dengan akurat menambahkan umur 1 hari setiap 60 detik dari umur 0 hari sampai dengan 49 hari. Pembuatan larutan nutrisi dapat berjalan secara otomatis ditandai dengan respon aktuator pada kondisi pengisian air, pencampuran nutrisi $\mathrm{AB}$ Mix dan sirkulasi dengan kadar TDS larutan nutrisi yang dihasilkan rata-rata sebesar 640 ppm, 716 ppm, 833 ppm dan 862 ppm. 


\section{Daftar Pustaka}

[1] A. D. Susila, Sistem Hidroponik, Bahan Ajar Dasar Dasar Hortikultura, Fakultas Pertanian Institut Pertanian Bogor, 2013, [on-line]. Tersedia: https://id.scribd.com/document/178242325/Modul-5-Sistem-Hidroponik. $\quad[15$ Februari 2019].

[2] P. L. Romadloni, Rancang Bangun Sistem Otomasi Hidroponik NFT (Nutrient Film Technique). Bandung: Telkom University, 2015.

[3] M. S . Asmana, S. H. Abdullah dan G. M. D. Putra, "Analisis Keseragaman Aspek Fertigasi pada Desain Sistem Hidroponik dengan Perlakuan Kemiringan Talang", Jurnal Ilmiah Rekayasa Pertanian dan Biosistem, vol.5, no. 1, Maret 2017.

[4] R. Rosliani dan N. Sumarni, Budidaya Tanaman Sayuran dengan Sistem Hidroponik, Bandung : Balai Penelitian Tanaman Sayuran, 2005, hal. 2-16.

[5] W. Sari, M. Idrus dan Surya, "Produktivitas Air Beberapa Varietas Selada dengan Sistem Irigasi NFT (Nutrient Film Technique) di PT. Momenta Agrikultura Lembang Bandung Barat", Jurnal Ilmiah Teknik Pertanian, vol. 7, no. 3, Desember 2015.

[6] S. Nisha et al, "Hydroponics as An Advanced Technique for Vegetable Production : An Overview", Journal of Soil and Water Conservation, vol.17, no. 4, 2018.

[7] Susilawati, Dasar-dasar Bertanam Secara Hidroponik, Palembang : Unsri Press, 2019, hal. 79.

[8] D. Eridani, O. Wardhani, and E. D. Widianto, "Designing and Implementing the Arduino-based Nutrition Feeding Automation System of a Prototype Scaled Nutrient Film Technique (NFT) Hydroponics using Total Dissolved Solids (TDS) Sensor", in Proc. of $4^{\text {th }}$ International Conference on Information Technology, Computer and Electrical Engineering (ICITACEE), Semarang, Indonesia, October 2017.

[9] A. W. Wibowo, A. Suryanto dan A. Nugroho, "Kajian Pemberian Berbagai Dosis Larutan Nutrisi dan Media Tanam Secara Hidroponik Sistem Substrat Pada Tanaman Kailan (Brassica oleracea L)", Jurnal Produksi Tanaman, vol. 5, no. 7, Juli 2017.

[10] R. Y. Koswara, "Otomatisasi Pengendalian Cara Pengairan dan Pemberian Nutrisi pada Sistem Tanam Hidroponik untuk Tanaman Selada (Lactuca sativa L.)", Jurnal Fisika UNY, Agustus 2016.

[11] P. Sihombing, N. A. Karina, J. T. Tarigan, and M. I. Syarif, “Automated Hydroponics Nutrition Plants Systems using Arduino Uno Microcontroller Based on Android", Journal of Physics Conference Series, vol. 978, no. 1, Maret 2018.

[12] T. Sugiharto, S. T. Rasmana dan I. Puspasari, "Pengaturan Air dan Nutrisi Secara Otomatis Pada Tanaman Hidroponik", Journal of Control and Network Systems, vol. 5, no. 2, 2016.

[13] Haryanto, Dwi dan K. N. Nurwijayanti, "Simulator Sistem Pengairan Otomatis Tanaman Hidroponik Dengan Arduino", TESLA: Jurnal Teknik Elektro, vol. 20, no. 2, 2019.

[14] F. U. Umi, Y. N. Akhmadi dan Sanyoto, Jago Bertanam Hidroponik untuk Pemula, Jakarta Selatan : AgroMedia Pustaka, 2018, hal. 79.

[15] Jimmi Sitepu, Tutorial Cara Menggunakan EEPROM Arduino Tanpa Library, Lengkap dengan Programnya [Online], https://mikroavr.com/program-eeprom-arduino/, diakses tanggal 19 Juli 2020. 